\title{
EDUKASI KESEHATAN REPRODUKSI REMAJA (KRR) DALAM RANGKA PEMBIASAAN PERSONAL HYGIENE BAGI REMAJA PUTERI DI DESA LANGENSARI KECAMATAN SOLOKANJERUK KABUPATEN BANDUNG
}

\author{
Prihantini $^{1^{*}}$, Kurniawati ${ }^{2}$, Rostika $D^{3}$ \\ ${ }^{1-3}$ Universitas Pendidikan Indonesia Kampus Cibiru \\ Email Korespondensi: prihantini@upi.edu
}

\begin{abstract}
ABSTRAK
Edukasi Kesehatan Reproduksi Remaja tidak semata-mata bertujuan mencegah penyakit atau gangguan lainnya tetapi juga bertujuan untuk menanamkan pembiasaan seseorang memiliki perilaku personal hygiene atau kebersihan diri terhadap system, fungsi, dan proses reproduksi. Alat reproduksi bagi remaja puteri merupakan organ tubuh yang sensitif dan memerlukan perawatan khusus. Penelitian terdahulu menyimpulkan bahwa 43,3 juta jiwa remaja berusia 15-24 tahun berperilaku hygiene tidak sehat dan salah dalam merawat area genital. Tujuan kegiatan pengabdian masyarakat adalah untuk membekali literasi kesehatan, pengetahuan kesehatan, dan pola hidup sehat kepada kelompok sasaran yang terdiri dari remaja putri, ibu-ibu rumah tangga, guru pembina Usaha Kesehatan Sekolah (UKS) jenjang sekolah dasar, dan guru bimbingan konseling jenjang sekolah menengah pertama dan sekolah menengah umum/kejuruan. Metode yang diterapkan adalah edukasi kelompok dan demonstrasi perawatan organ reproduksi dengan media visual power point dan pemberian buku saku kesehatan reroduksi remaja putri. Hasil yang diperoleh $80 \%$ dari peserta yang hadir dapat menjawab evaluasi tentang akibat dari tidak membiasakan personal hygiene organ reproduksi dan cara merawat organ reproduksi dengan benar. Kesimpulan, peserta sangat antusias dan terwujud komitmen Kelompok Kerja Pemberdayaan Kesejahteraan Keluarga (Pokja PKK) bahwa edukasi kesehatan reproduksi remaja putri diagendakan dalam pertemuan rutin.
\end{abstract}

Kata kunci: kesehatan reproduksi remaja, personal hygiene

\begin{abstract}
Adolescent Reproductive Health Education is not only aimed at preventing diseases or other disorders but also aims at instilling a person's habit of having personal hygiene behavior towards the reproductive system, function and process. The reproductive organs for young women are sensitive organs and require special care. Previous research has concluded that 43,3 million adolescents aged 15-24 years have unhealthy hygiene behaviour and are wrong in caring for the genital area. The purpose of community service activities is to provide health literacy, health knowledge, and healthy lifestyles to the target group consisting of young women, housewives, couch teachers of primary school health efforts, and counseling teachers at junior high school level and
\end{abstract}


general/vocational high school. The method applied was group education and demonstration of reproductive organ care using visual power point media and the provision of reproductive health pocket books for young women. The results obtained were $80 \%$ of participants could answer evaluations about the consequences of not familiarizing themselves with the personal hygiene of the reproductive organs and how properly care for the reproductive organs. In conclusion, the participants were very enthusiastic and realized the commitment of the Family Welfare Empowerment Working Group that adolescent girls' reproductive health education was scheduled in routine meetings.

Keywords: adolescent reproductive health, personal hygiene.

\section{PENDAHULUAN}

Kesehatan reproduksi remaja (KRR) menurut World Health Organization (WHO) adalah suatu keadaan sejahtera fisik, mental, dan sosial secara utuh tidak semata-mata bebas dari penyakit atau kecacatan yang berkaitan dengan system reproduksi, fungsi dan prosesnya (Prijatni dan Rahayu, 2016). Kesehatan reproduksi remaja juga menjadi isu penting dalam Sustainable Devolopment Goals (SDGs) dan International Conference of Population and Devolopment (ICPD) di Kairo tahun 1994. Delegasi dari 176 negara termasuk Indonesia menghasilkan kesepakatan untuk membentuk komisi kesehatan reproduksi. Perhatian dunia internasional tentang kesehatan reproduksi didasari oleh argumen rasional, sebagaimana disebutkan oleh Cherry, Baltag, dan Dillon (2017:170) 'the rationale for focusing on adolescent health and rights has to do with young people facing particular risks that may have concequences not only for their immediate future but also for the rest of their lives'.

Data Survei yang dilakukan World Health Organization (WHO) di beberapa negara, remaja puteri berusia 10-14 tahun mempunyai permasalahan terhadap reproduksinya. Pada tahun 2010 angka kejadian infeksi saluran reproduksi (ISR) tertinggi di dunia adalah pada usia remaja yang mencapai 35\%-42\%. Kementerian Kesehatan Republik Indonesia Tahun 2015 sebagaimana dikutip oleh Surmiasih (2019), sebanyak 43,3 juta jiwa remaja berusia 15-24 tahun berperilaku hygiene tidak sehat. Penelitian Wijayanti (2014) menyimpulkan bahwa remaja puteri sering salah dalam membersihkan area genital, membasuh organ genital dari arah belakang ke depan, membersihkan organ narche genetalia menggunakan sabun biasa atau cairan pembersih, menabur bedak di sekitar organ genital, atau menyemprotkan parfum ke dalam vagina. Hasil penelitian ini memperkuat bahwa remaja puteri perlu diberikan bekal pengetahuan tentang perawatan organ reproduksi.

Edukasi KRR pada remaja puteri perlu diutamakan karena erat hubungannya dengan sifat organ reproduksi yang sensitif dan membutuhkan pembiasaan khusus perilaku personal hygiene. Edukasi KRR tidak semata-mata bertujuan mencegah penyakit atau gangguan lainnya tetapi juga berkaitan dengan pembiasaan seseorang memiliki perilaku personal hygiene atau kebersihan diri terhadap system, fungsi, dan proses reproduksi. Edukasi KRR bagi remaja puteri masih jarang dibicarakan oleh masyarakat karena ada kesan 'tabu' apabila masalah tersebut dibicarakan secara terbuka, bahkan melalui proses pendidikan kesehatan di sekolah pun masih ada kesan sama. Pengetahuan dan perawatan yang baik merupakan faktor penentu dalam 
memelihara kesehatan reproduksi (Ratna, 2010). Demikian pula persepsi yang salah atau kurang menyebabkan perilaku kesehatan yang dilakukan remaja tidak maksimal dalam perawatan organ reproduksi (Surmiasih, 2019).

Pengabdian kepada masyarakat tentang Edukasi Kesehatan Reproduksi Remaja (KRR) dalam rangka Pembiasaan Personal Hygiene bagi Remaja Puteri bertujuan untuk membekali literasi kesehatan, pengetahuan kesehatan, dan pola hidup sehat kepada kelompok sasaran yang terdiri dari remaja putri, ibuibu rumah tangga, guru pembina usaha kesehatan sekolah jenjang sekolah dasar, dan guru bimbingan konseling jenjang sekolah menengah pertama dan sekolah menengah umum/kejuruan.

\section{MASALAH}

Desa Langensari kecamatan Solokanjeruk Kabupaten Bandung, teridentifikasi jumlah penduduk usia remaja mencapai $31,284 \%$ dari keseluruhan penduduk desa yang berjumlah 11.482 jiwa. Di desa Langensari banyak pendatang yang sebagian besar adalah karyawan pabrik, rata-rata usia remaja dan sebagian besar adalah remaja puteri. Hasil wawancara dengan Bidan Desa dan pengurus Kelompok Kerja Pemberdayaan Kesejahteraan Keluarga (Pokja PKK) Desa, diperoleh informasi bahwa belum pernah dilaksanakan penyuluhan tentang kesehatan reproduksi remaja khusus remaja puteri, baik oleh PUSKESMAS, Dinas Pendidikan, maupun dari institusi lain. Oleh karena itu kegiatan edukasi KRR dalam rangka pembiasaan personal hygiene bagi remaja puteri menjadi pertimbangan utama tim untuk dilaksanakan di desa Langensari.
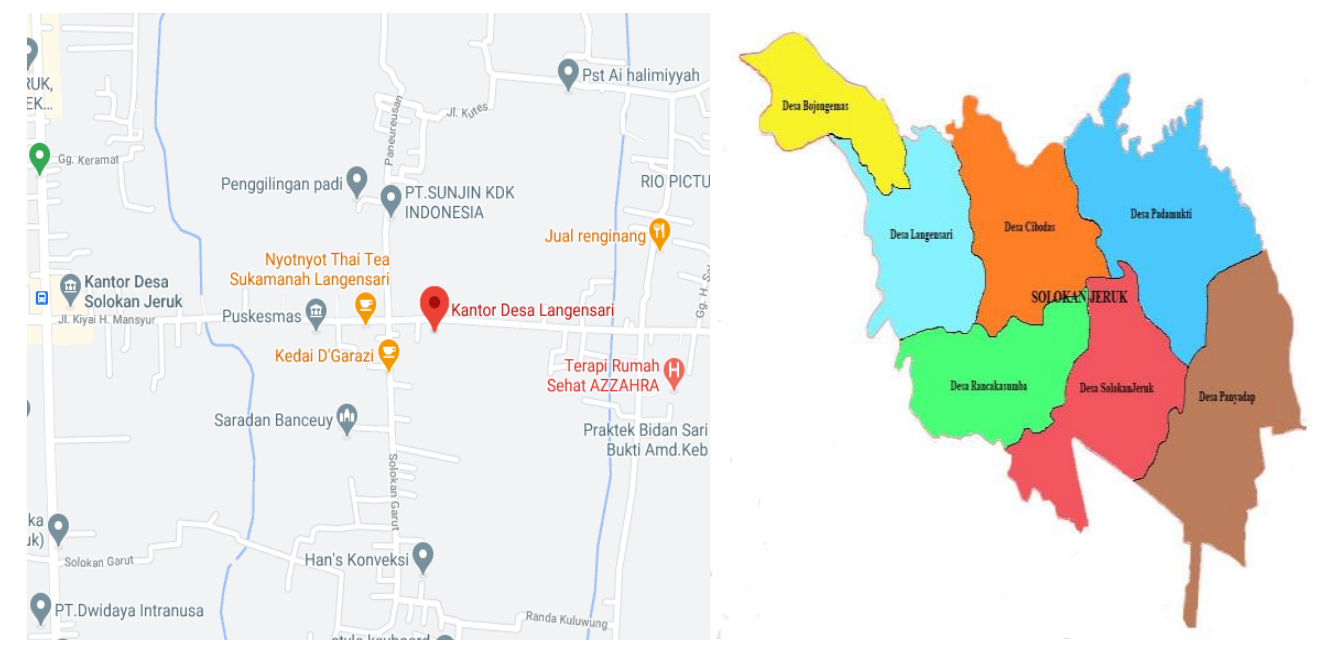

Gambar 1. Lokasi Pelaksanaan Edukasi KRR dan Personal Hygiene bagi Remaja Puteri

\section{METODE PELAKSANAAN}

\section{a. Tahap persiapan}

Pelaksanaan kegiatan edukasi diawali dengan rapat persiapan antara tim dosen UPI Kampus Cibiru, Bidan Desa, dan mahasiswa yang terlibat dalam pengabdian. Keputusan peserta terdiri dari pengurus Kelompok Kerja PKK, Pengurus Karang Taruna khusus puteri, guru pembina Usaha Kesehatan Sekolah (UKS) SD, SMP, dan SMA, serta pengurus OSIS SMP dan SMA khusus puteri yang ada di Kecamatan Solokan Jeruk, jumlah seluruhnya 50 peserta. Dalam upaya efektifitas proses peer-education antar remaja diputuskan 
dibuat Buku Saku KRR Remaja Puteri, mengingat masih ada kesan tabu bila edukasi KRR dilaksanakan secara terbuka.

\section{b. Tahap pelaksanaan}

Pelaksanaan pada tanggal 5 Agustus 2019 di kantor Desa Langensari Kecamatan Solokanjeruk Kabupaten Bandung. Pelaksanaan edukasi berlangsung mulai pukul 08.30-11.30 WIB, diawali dengan acara pembukaan, sambutan perangkat desa, dan pengarahan dari PUSKESMAS Kecamatan Solokanjeruk. Sebelum materi, dilaksanakan tanya jawab dan brainstorming dengan peserta selama 30 menit untuk mengukur pengetahuan perawatan organ reproduksi wanita. Materi edukasi mencakup pentingnya perawatan organ reproduksi, menjaga kebersihan ketika datang menstruasi dan menghindari perilaku negatif yang dapat merugikan diri sendiri, dampak yang ditimbulkan apabila tidak melakukan personal hygiene, dan demonstrasi visual perawatan organ reproduksi. Media dan alat yang digunakan adalah visual power point dan proyektor.

\section{c. Tahap evaluasi}

Pada akhir kegiatan dilaksanakan evaluasi secara lisan untuk mengetahui pemahaman peserta tentang cara menerapkan personal hygiene organ reproduksi.

\section{HASIL DAN PEMBAHASAN}

Edukasi merupakan terjemahan dari 'education' yang berarti pendidikan, dengan demikian kegiatan edukasi KRR dan personal hygiene dapat dikatakan sebagai salah satu bentuk pendidikan kesehatan. Menurut Ayu (2020) pendidikan kesehatan adalah salah satu dari strategi promosi kesehatan, oleh karena itu kegiatan edukasi KRR dan personal hygiene kepada remaja putri diharapkan dapat mempromosikan pengetahuan tentang KRR dan membangun persepsi kepada remaja putri tentang pentingnya membiasakan personal hygiene dalam kehidupan sehari-hari. Hal ini mengingat bahwa terdapat hubungan lurus antara pengetahuan dan persepsi dengan informasi yang diperoleh oleh individu (Susilawati, Nilakesuma, dan Surya, 2019). Melalui edukasi KRR dan personal hygiene dapat dipromosikan informasi tentang pengetahuan KRR dan pentingnya pembiasaan personal hygiene bagi remaja putri, karena pengetahuan remaja tentang kesehatan reproduksi tergolong rendah disebabkan minimnya informasi yang diperoleh remaja atau mendapatkan infomasi tentang kesehatan reproduksi dari sumber yang salah (Listina dan Baharza,2020).

Kegiatan edukasi KRR dalam rangka pembiasaan personal hygiene kepada remaja putri di desa Langensari terlaksana sesuai rencana. Peserta yang hadir semuanya berjenis kelamin wanita sebagaimana undangan yang telah didistribusikan sejumlah. Peserta berjumlah 50 orang meliputi sebagai berikut.

Tabel 1 Peserta Kegiatan Edukasi KRR dalam rangka Pembiasaan Personal Hygiene Remaja Putri

\begin{tabular}{ccc}
\hline No & Unsur & $\begin{array}{c}\text { Jumlah } \\
\text { (orang) }\end{array}$ \\
\hline 1. & Bidan Desa & 1 \\
\hline
\end{tabular}




\begin{tabular}{llr}
\hline 2. & Karang Taruna perwakilan 16 RW & 16 \\
\hline 3. & Pengurus PKK Desa & 5 \\
\hline 4. & Perwakilan Pengurus PKK RW & 16 \\
\hline 5. & Kepala SD dan Guru Pembina UKS SD & 6 \\
\hline 6. & Guru Pembina OSIS SMP & 1 \\
\hline 7. & Guru Pembina OSIS SMA & 1 \\
\hline 8. & Pengurus OSIS SMP & 2 \\
\hline 9. & Pengurus OSIS SMA & 2 \\
\hline & Total Peserta & 50 \\
\hline
\end{tabular}

Pertimbangan pemilihan peserta dari tiap unsur sebagaimana terlihat pada tabel di atas, diharapkan penyebaran informasi dapat terjadi peer education antar sesama remaja didalam organisasi Karang Taruna dan anggota OSIS putri di SMP dan SMA, sedangkan untuk jenjang SD dipercayakan kepada guru pembina Usaha Kesehatan Sekolah (UKS) dan Kepala Sekolah karena siswa SD lebih mudah diarahkan oleh guru. Adapun Bidan Desa dan pengurus PKK diharapkan dapat terjadi peer education melalui kegiatan PKK. Dengan mengundang unsur-unsur tersebut, pelaksanaan edukasi KRR dalam rangka pembiasaan personal hygiene remaja putri mendapatkan respon positif dari pihak perangkat desa, Pokja PKK, PUSKESMAS, dan Bidan Desa. Foto pelaksanaan dan pasca kegiatan tampak sebagai berikut.

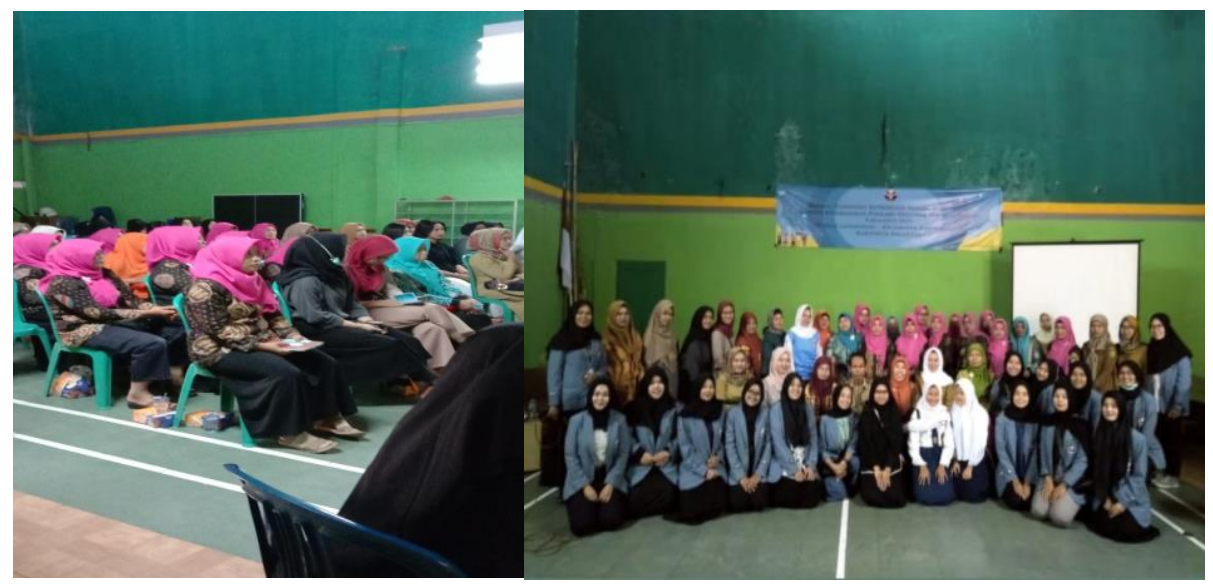

Gambar 2. Foto Peserta Edukasi KRR dan Pasca Kegiatan

Tujuan yang dicapai melalui edukasi KRR dalam rangka pembiasaan personal hygiene remaja puteri, yaitu literasi kesehatan (health literacy), pengetahuan kesehatan (health knowledge), dan pola hidup sehat (health lifestyles). Personal hygiene diharapkan menjadi kebiasaan remaja puteri untuk selalu menjaga kebersihan area genital dalam kehidupan sehari-hari, menjaga kebersihan pada saat datang menstruasi, dan menyadari adanya resiko merugikan dengan datangnya menstruasi apabila remaja tidak memiliki sikap self protective dalam pergaulan.

Kegiatan edukasi mengundang kelompok sasaran yang diasumsikan merupakan partner remaja, yakni organisasi remaja Karang Taruna dan Organisasi Siswa Intra Sekolah (OSIS), Pengurus PKK yang diharapkan dapat menyebarkan informasi di kalangan ibu-ibu rumah tangga. Hal ini mengacu pada Kementerian Kesehatan (2015) bahwa partner diskusi atau dialog tentang kesehatan reproduksi yang paling disukai remaja, berturut-turut adalah teman 
sebaya, guru, dan ibunya. Melalui interrelasi partnership tersebut diharapkan terjadi peer education sehingga bergulir informasi KRR dan personal hygiene remaja puteri yang dinamakan efek bola salju, yakni perluasan informasi secara meluas dan terus menerus. Untuk mengefektifkan proses peer education, maka dalam pelaksanaan edukasi KRR dibagikan kepada peserta Buku Saku KRR Remaja Puteri.

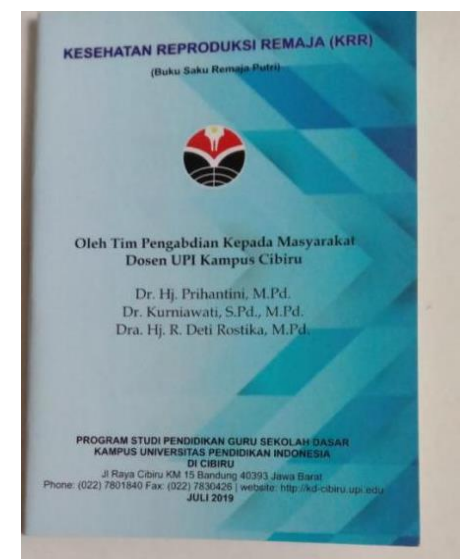

Gambar 3. Buku Saku KRR Remaja Puteri

\section{KESIMPULAN}

Kegiatan edukasi KRR dalam rangka pembiasaan personal hygiene remaja puteri terlaksanakan dengan lancar sesuai perencanaan. Peserta yang hadir sejumlah 50 orang sesuai rencana. Peserta antusias, terbukti pada kegiatan evaluasi $80 \%$ peserta dapat menjawab pertanyaan lisan yang diberikan oleh nara sumber. Antusias peserta terwujud dalam komitmen Pokja PKK dengan menindaklanjuti menjadwalkan edukasi melalui pertemuan rutin Pokja PKK Desa.

\section{Ucapan Terima Kasih}

Ucapan terima kasih disampaikan kepada Program Studi S1 PGSD dan Direktur Kampus UPI di Cibiru yang telah memberikan izin pelaksanaan pengabdian kepada masyarakat dan memberikan subsidi biaya melalui RKAT tahun 2019. Ucapan terima kasih tak terhingga disampaikan kepada dr Hebert Adrianto, S.Si, M.Ked. Trop. dosen Fakultas Kedokteran Universitas Ciputra Surabaya yang telah berkenan menjadi konsultan baik dalam memotivasi penulis maupun dalam penyusunan Buku Saku KRR Remaja Puteri.

\section{DAFTAR PUSTAKA}

Ayu, Ira.M. (2020) Program Peningkatan Pengetahuan Kesehatan Reproduksi Remaja di SMK “ $X$ " Tangerang Raya.Jurnal Kreativitas Pengabdian Kepada Masyarakat (PKM). P-ISSN:2615-0912. E-ISSN:2622-6030. Volume 3. Nomor 1, April 2020. Hal 87-95. http://ejurnalmalahayati.ac.id/index.php/ kreativitas/ index.

Cherry, A.L. Baltag, Valentina. and Dillon, Mary E. (2017). International Handbook on Adolescent Health and Development the Public Health Response. Switzerland: Springer International Publishing. 
Listina,F. dan Baharza, S.N. (2020). Penyuluhan Mengenai Kesehatan Reproduksi Remaja Di SMKN 6 Bandar Lampung. Jurnal Kreativitas Pengabdian Kepada Masyarakat (PKM). P-ISSN:2615-0912. E-ISSN:26226030. Volume 3. Nomor 1, April 2020. Hal 34-38. http:// ejurnalmalahayati.ac.id/index.php/kreativitas/index.

Prijatni,I. dan Rahayu,S. (2016). Kesehatan Reproduksi dan Keluarga Berencana (Modul Bahan Cetak Kebidanan). Jakarta: Kementerian Kesehatan Pusdik SDM Kesehatan. http://bppsdmk.kemkes.go.id/ pusdiksdmk/wp-content/uploads/2017/08/Kespro-dan-KBKomprehensif.pdf.

Ratna DP. (2010). Pentingnya menjaga organ kewanitaan. Jakarta: Indeks.

Rom Korin, Maya. (2016). Health Promotion for Children and Adolescents. (eBook). New York: Springer Science+Business Media.

Surmiasih. Winarsi, N. Wahidun. (2019) Pendidikan Kesehatan Terhadap Kemampuan Remaja Puteri Dalam Perawatan Organ Reproduksi. Holistik Jurnal Kesehatan. Volume 13. No. 1. Maret 2019:76-83. https:// doi.org/10.33024/hjk.v13i1.1045.

Susilawati,D. Nilakesuma, N.F. Surya,D.O. (2019). Penyuluhan Kesehatan Reproduksi Remaja di SMP Pertiwi Siteba Padang. Jurnal Kreativitas Pengabdian Kepada Masyarakat (PKM). P-ISSN:2615-0912. E-ISSN:26226030. Volume 2. Nomor 2, Oktober 2019. Hal 166-170. http:// ejurnalmalahayati.ac.id/index.php/kreativitas/index.

Wijayanti, Wakhidah, U. (2014). Hubungan Tingkat Pengetahuan Remaja Puteri tentang Infeksi Genitalia Eksterna dan Perilaku Vulva Hygiene kelas XI di Man 1 Surakarta. Surakarta: Jurnal Kebidanan STIKES PKU Muhammadiyah Surakarta.Vol.VI No 1. http: //dx.doi.org/ 10.35872/ jurkeb. v6i1.129.

World Health Organization (WHO). (1998). Health Promotion Glossary Genewa. Available from: http://www.who.inthealthpromotion.pdf.

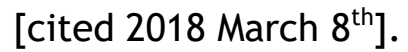

Undang-undang Republik Indonesia Nomor 40 Tahun 2009 tentang Kepemudaan.https://www.dpr.go.id/dokjdih/document/uu/UU_2009_4 $0 . p d f$ 